\title{
Evaluation of nine different types of enuresis alarms
}

\author{
K M GOEL, R B THOMSON, E M GIBB, AND T F McAINSH \\ Royal Hospital for Sick Children and Department of Clinical Physics and Bio-Engineering, Glasgow
}

SUMMARY One hundred enuretic children were treated in closely supervised trial conditions with nine commonly used enuresis alarm systems available commercially in the United Kingdom. Although there was little difference between the systems in terms of their effectiveness in stopping bed wetting, parents preferred the Eastleigh and Urilarm De-Luxe models which had distinct advantages in respect of false alarms, breakdowns, and durability of pads. Enuresis alarms that perform poorly in these respects may lead to loss of enthusiasm and non-compliance. The systems vary widely in price, but a private buyer may find a cheaper alarm just as effective.

Enuresis alarms have played a vital and effective role in the treatment of bed wetting in children over the past two decades, ${ }^{1}$ and they undoubtedly effect a cure in a higher proportion of enuretic children than can be achieved by other forms of treatment. ${ }^{2-5}$ Manufacturers have produced different alarm systems for families with slightly different needs but all make use of the electrical conductivity of urine. The main purpose of the present study was to evaluate the technical performance of some of the commonly used alarm systems currently available in the United Kingdom.

\section{Patients and methods}

As shown in Table 1, nine types of alarm system were obtained from six manufacturers. One hundred enuretic children (62 boys and 38 girls) underwent a single course of conditioning therapy. The ages of the children at the time of the study ranged from 7 to 14 years (mean 91/2 years). Sixty children had primary and 40 had secondary enuresis. Sixteen children belonged to social class I and II, 39 to social class III, and 45 to social class IV and V families. A family history of nocturnal enuresis in parents or siblings was positive in 43 children.

Children were selected for the study according to the following critera:

(a) Aged 7 years of age or over.

(b) Enuretic on average for three nights or more per week.

(c) No underlying urinary tract pathology.

(d) No satisfactory response to either simple supportive measures (for example fluid restriction, rewards, star charts, lifting and waking) or trial of tricyclic antidepressant drugs, or both. (e) Understanding of and ability to follow the alarm routine properly.

(f) At least one parent prepared to cooperate actively in the treatment.

After selection for the study both the parent and child were seen at a specially arranged 'enuresis clinic' at this hospital, where they were given an explanation of the treatment rationale and a demonstration of the alarm system being used. The trial was confined to systems which incorporated a detector pad placed on the bed and an alarm near the bed. Manufacturers' instructions were also given to the parent. The parents were supplied with cotton drawsheets to ensure that the bed linen used during the study was uniform. The parent was not asked to alter sleeping arrangements unless he or she or a willing family member was unable to hear and waken up with the alarm. The children were then asked to use the enuresis alarm every night until they had completed a maximum trial period of 20 weeks. Our criterion of initial success was less than four wet nights in the 28 nights before the conditioning therapy was stopped. The family had several home visits from a health visitor appointed for the study to assess and ameliorate any practical difficulties with the alarm equipment. In instances of alarm malfunction, the health visitor noted the nature of the fault and arranged for its repair (when this was beyond the parents' capabilities) and speedy return to service. Notes were also made of the durability of the different types of enuresis mats provided with each particular model of alarm and on their acceptance by the parents, paying particular attention to the number of false alarms reported by the parents. Follow up took place at the clinic at monthly 748 
Table 1 Details of the enuresis alarms tested

\begin{tabular}{|c|c|c|c|}
\hline Alarm model & Manufacturer's address & $\begin{array}{l}\text { Price } \\
\text { including pads } \\
\text { (in 1983) }\end{array}$ & $\begin{array}{l}\text { No of children } \\
\text { issued with } \\
(n=100)\end{array}$ \\
\hline 2. Chiron Mark III & $\begin{array}{l}\text { Down's Surgical Co Ltd, Church Path, Mitcham, } \\
\text { Surrey CR4 3UE }\end{array}$ & $£ 35.95$ & 12 \\
\hline $\begin{array}{l}\text { 3. Eastleigh Ministry of } \\
\text { Health }(\mathrm{MOH}) \text { I }\end{array}$ & $\begin{array}{l}\text { N H Eastwood \& Son Ltd. } 70 \text { Nursery Road, } \\
\text { London. N14 5QH }\end{array}$ & $£ 31 \cdot(0)$ & 13 \\
\hline $\begin{array}{l}\text { 4. Eastleigh } \mathrm{MOH} \mathrm{I} \\
\text { and Booster }\end{array}$ & $\begin{array}{l}\text { N H Eastwood \& Son Ltd. } 70 \text { Nursery Road. } \\
\text { London N14 5QH }\end{array}$ & $£ 40 \cdot 50$ & 13 \\
\hline 5. Headingley & $\begin{array}{l}\text { Headingley Scientific Services. } 20 \text { Cottage Road. } \\
\text { Leeds. LS6 4DD }\end{array}$ & $£ 35 \cdot(0)$ & 9 \\
\hline $\begin{array}{l}\text { 6. Headingley with } \\
\text { Silent Wakener }\end{array}$ & $\begin{array}{l}\text { Headingley Scientific Services, } 20 \text { Cottage Road, } \\
\text { Leeds LS6 4DD }\end{array}$ & $£ 52 \cdot(0)$ & 9 \\
\hline 7. Headingley with extension & $\begin{array}{l}\text { Headingley Scientific Services, } 20 \text { Cottage Road, } \\
\text { Leeds LS6 4DD }\end{array}$ & $£ 50 \cdot(00)$ & 5 \\
\hline 8. Urilarm De-Luxe & $\begin{array}{l}\text { F Gulliver Devices Ltd, The Mews, } \\
\text { 49/51 Station Road, London }\end{array}$ & f17.91 & 12 \\
\hline
\end{tabular}

study a further six months' follow up of the 45 children who responded to the alarm system was maintained by post or telephone.

\section{Results}

Details of false alarms, life of mat, alarm breakdowns, type of batteries, battery life, average cost of batteries per trial, sound level, and star ratings of different alarms are shown in Tables 2, 3, and 4.

Enuresis mats. The factor of greatest importance in differentiating between the enuresis alarm systems was the type of enuresis mat supplied.

\section{Comparison of enuresis mats}

Type 1. This comprised a single PVC sheet, approximately $45 \mathrm{~cm}$ square (active area: $30 \mathrm{~cm} \times 27 \mathrm{~cm}$ ), with two separate, $15 \mathrm{~mm}$ broad stitched-on aluminium metal ribbons arranged in two parallel, interlacing spirals. This type of mat was supplied with the Astric and Headingley alarms.

The useful life of these single sheet enuresis mats during the trial extended from 5 to 13 weeks and was 7 weeks on average. The mats were reported to be difficult to dry completely after bed wetting. They were very pliable and tended to wrinkle and ruck up, causing false alarms in some instances. Parents tended not to make use of the eyelets provided on the mats for tying them down to the bed. All mats which became faulty became so as a result of the ribbon foil cracking or splitting. Since this investigation the supplier is providing a bridging wire running under the foil to ensure that when the foil does crack, the mat continues to function.

Type 2. This mat comprised a pair of wire mesh

Table 2 Technical performance of each of the alarm systems

\begin{tabular}{|c|c|c|c|c|c|c|}
\hline $\begin{array}{l}\text { Alarm model } \\
\text { (No of subjects) }\end{array}$ & $\begin{array}{l}\text { Average no of } \\
\text { nights disturbed by } \\
\text { false alarms in } \\
\text { whole trial period }\end{array}$ & Durability of mats & $\begin{array}{l}\text { No of alarm } \\
\text { breakdowns } \\
\text { per } 10 \\
\text { alarms used }\end{array}$ & $\begin{array}{l}\text { Type of } \\
\text { batteries }\end{array}$ & $\begin{array}{l}\text { Average } \\
\text { battery life } \\
\text { (weeks) }\end{array}$ & $\begin{array}{l}\text { Average cost } \\
\text { of batteries } \\
\text { per trial } \\
\text { (in 1983) }\end{array}$ \\
\hline $\begin{array}{l}\text { Urilarm De-Luxe } \\
(\mathrm{n}=12)\end{array}$ & 3 & $15-21$ weeks & 1 & $2 \times \mathrm{HP} 2(3 \mathrm{~V})$ & 3 & $£ 1.74$ \\
\hline $\begin{array}{l}\text { Headingley } \\
\qquad(n=23)\end{array}$ & 11 & 5-13 weeks & 4 & $\begin{array}{l}4 \times 1 \cdot 5 \mathrm{~V} \\
\mathrm{MN} 1500(6 \mathrm{~V})\end{array}$ & $>20$ & $£ 1.90$ \\
\hline $\begin{array}{l}\text { Wessex } \\
\quad(n=13)\end{array}$ & 6 & 5 weeks & 5 & $1 \times$ PP9 $(9 \mathrm{~V})$ & 12 & $f 1 \cdot 29$ \\
\hline $\begin{array}{l}\text { Chiron Mark III } \\
(n=12)\end{array}$ & 9 & 9 days -10 weeks & 1 & $4 \times H P 11(6 V)$ & 10 & $f 1.42$ \\
\hline $\begin{array}{l}\text { Eastleigh } \\
\quad(n=26)\end{array}$ & 2 & 11-19 weeks & 1 & $1 \times \mathrm{PJ} 996(6 \mathrm{~V})$ & $>20$ & $£ 2 \cdot 10$ \\
\hline $\begin{array}{l}\text { Astric Dry-bed } \\
(n=14)\end{array}$ & 9 & 7 weeks & 1 & $4 \times \mathrm{HP7}(6 \mathrm{~V})$ & $>20$ & $£(0 \cdot 76$ \\
\hline
\end{tabular}


Table 3 Star ratings of practical evaluation of each of the alarm systems

\begin{tabular}{|c|c|c|c|c|c|}
\hline $\begin{array}{l}\text { Enuresis pads } \\
\text { and alarm system }\end{array}$ & False alarms & $\begin{array}{l}\text { Durability } \\
\text { of pads }\end{array}$ & $\begin{array}{l}\text { Alarm } \\
\text { breakdowns }\end{array}$ & $\begin{array}{l}\text { Battery } \\
\text { life }\end{array}$ & $\begin{array}{l}\text { Average cost of } \\
\text { batteries per trial }\end{array}$ \\
\hline \multicolumn{6}{|l|}{ Wire mesh mats } \\
\hline Eastleigh & $* * * * *$ & $* * * * *$ & $* * * *$ & $* * * *$ & $* *$ \\
\hline Urilarm De-Luxe & $* * * *$ & $* * * * *$ & $* * * *$ & *** & $* * * *$ \\
\hline \multicolumn{6}{|l|}{ Aluminium foil mats } \\
\hline Wessex & $* *$ & $*$ & $*$ & $* * *$ & $* * *$ \\
\hline Chiron Mark III & $*$ & $*$ & $* * * *$ & $* * *$ & $* *$ \\
\hline \multicolumn{6}{|l|}{ Plastic mats } \\
\hline Astric Dry-bed & $*$ & $* *$ & $* * * *$ & $* * * * *$ & $* * * * *$ \\
\hline Headingley & $*$ & ** & $*$ & $* * * * *$ & $* *$ \\
\hline
\end{tabular}

Key to star ratings $* * * * *=$ Excellent

**** = Extremely good

*** $=$ Satisfactory

** $\quad$ = Not entirely satsifactory

* $\quad$ Poor

Table 4 Comparison of different enuresis alarm systems in relation to wakening the enuretic child

\begin{tabular}{ll}
\hline $\begin{array}{l}\text { Alarm model } \\
\text { (Sound level at a distance } \\
\text { of one metre from alarm) }\end{array}$ & Child wakening reliability \\
\hline Urilarm De-Luxe (88 dBA) & \\
Headingley with Silent Wakener (78 dBA) & Effective \\
Headingley with extension (67 dBA) & Lestive \\
Headingley alone (70 dBA) & Less effective \\
Wessex (89 dBA) & Less effective \\
Chiron Mark III (85 dBA) & Effective \\
Eastleigh alone (89 dBA) & Effective \\
Eastleigh with extension $(86 \mathrm{dBA})$ & Effective \\
Astric Dry-bed $(79 \mathrm{dBA})$ & Less effective \\
\hline
\end{tabular}

*Each alarm was tested by Sound Level Metal Model, Peters CS 181A.

mats with edge binding, area some $50 \mathrm{~cm} \times 30 \mathrm{~cm}$. It was supplied with the Urilarm and Eastleigh alarms. In the case of the latter model the two mats are made of dissimilar metals which serve as the poles of a battery-the urine acting as an electrolyte. (With all other mats, voided urine creates a low electrical resistance path between the conducting mats.)

The useful life of these wire mesh mats extended from 11 to 21 weeks. The health visitor's initial comments on this general type of mat were very favourable. Later it was reported that the mats were tending to curl up after several weeks' use. False alarms were appreciably fewer, however, with these mats than with the other types. With the Eastleigh mats (which because of their nature do not sound 'false' alarm when they touch) it was noted in a few instances-when the supplier's instructions on cleaning the mats were not followed rigorouslythat a deposit formed on the wire mesh, preventing the alarm from functioning-a condition which sometimes went undetected by the parents.

Type 3. Type 3 mats consisted of a pair of conducting sheets, the top one perforated with an array of $1 / 4$ inch diameter holes to let urine penetrate between the mats. Two types of sheet mat were available:

(a) Aluminium foil sheets, area $65 \mathrm{~cm} \times 40 \mathrm{~cm}$. These were supplied with the Down's Chiron and Wessex alarms.

(b) Plastic sheets with stitched on, looped cooper braiding. The active area of these mats was $28 \mathrm{~cm} \times 5$ $\mathrm{cm}$. This type of mat was available with the Wessex alarm.

Type 3 (a) foil mats lasted for 9 days to 10 weeks. They are regarded as expendable by the suppliers who recommend the purchase of two pairs of mats per alarm unit. These mats were difficult to care for, tending to disintegrate on being washed repeatedly after bed wetting. They were also inclined to wrinkle and ruck up beneath the patient. Numerous false alarms were reported.

Type 3 (b) mats had a life span of 11 to 22 weeks. Their operational acceptability was reported to be similar to the wire mesh mats.

\section{Design of enuresis mats}

No mats were entirely satisfactory and some thought should be given to an improved design. Clinical personnel distinctly prefer the wire mesh type of mat (type 2) presently available.

Battery life. Training an enuretic child to waken on the sounding of an enuresis alarm takes time. Before the trial it was intended that the training should last for 16 weeks; in the light of experience the period was extended to 20 weeks. Thus the life of the enuresis alarm batteries is an important consideration. Although purchasing and replacing batteries is a simple matter, it is yet another chore for parents who are already harassed. 
The battery life for the various alarm models is shown in Table 2. The Astric and Headingley alarms use modern, integrated circuit components which have a very low current consumption and there was no requirement to replace their batteries. The Urilarm De-Luxe alarm, however, required frequent battery changes. The Eastleigh alarm draws little current in its quiescent state and although the current drawn is relatively high in alarm mode, battery life is not a problem because a large capacity (but not inexpensive) battery is used (Ever Ready PJ 996) (Table 2).

Alarm breakdown. Although the repairs required were generally trivial in nature, they were outwith the capabilities of the parents and would have meant, in normal circumstances, the alarms being out of use.

\section{Astric alarm}

On three units, the flex between the alarm unit and the enuresis mat became disconnected within a jack plug. This was due to ineffective clamping of the flex. (The flex and the clamp provided were incompatible).

\section{Chiron alarm}

Only one trivial fault was reported. It was repaired by the health visitor.

\section{Eastleigh alarm}

On four occasions a connecting lead broke away from a stud connector and had to be resoldered.

Response time of alarms. Table 5 shows the responsiveness of the three types of enuresis pads used in the nine different alarm systems. The responsiveness of each alarm system (including the alarm unit, enuresis pad(s), and cotton sheet(s) was tested in the laboratory using $0.9 \% \mathrm{NaCl}$ solution from a syringe to simulate urine. The enuresis pad(s) and cotton sheet(s) were compressed to simulate the weight of the child. The three types of enuresis pads have noticeably different response times, not because of their construction but because of the number of bedding sheets required with each.

\section{Type 1}

These were quickest to respond to urine being voided because the urine has only one bed sheet (above the enuresis mat) to soak through to reach and bridge the conducting metallic foil.

\section{Type 2}

These pads were slower to respond than type 1 because the urine has two bed sheets to soak through to bridge the conducting mat pair, one bed sheet above the top enuresis mat and another between the mats.

\section{Type 3}

Type 3 pads had, inevitably, the slowest response. Not only are there two bed sheets for the urine to soak through, but the area of electrical contact is limited almost to the area of the perforations in the top enuresis mat.

Thirty seven of the enuretic children used the most sensitive single detector pads (type 1: Headingley and Astric alarms), 38 the less sensitive wire mesh (type 2: Urilarm De-Luxe and Eastleigh alarms), and 25 children used the least sensitive detector enuresis pads (type 3: Chiron and Wessex alarms). Seventeen of 37 children ( $46 \%$ ) using type 1,17 of $38(44 \%)$ using type 2 and 11 of $25(44 \%)$ using type 3 pads satisfied the criterion of initial arrest of bed wetting. As there was no difference between the three different types of enuresis mats in respect of success in training the children, it may be

Table 5 Comparison of the different enuresis pads and their responsivity to $0.9 \% \mathrm{NaCl}$ simulating urination

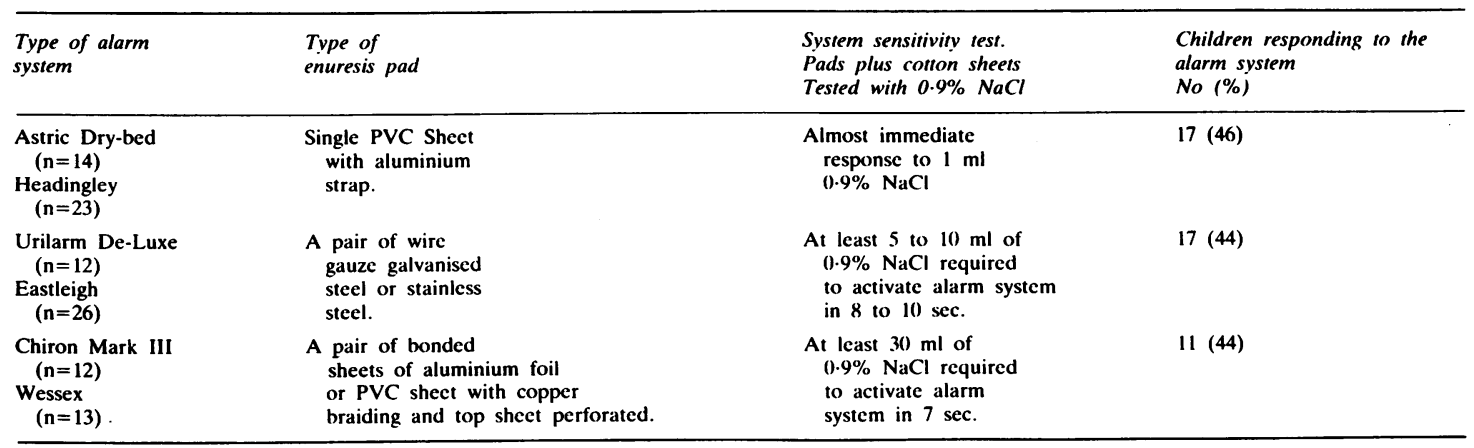


concluded that the clinical success rate is not related to the alarms' speed of response to urination.

\section{Discussion}

With regard to the technical performance of the commonly used alarm systems studied, none of the alarms in the trial deviated to any substantial extent in their construction or performance from the safety code governing their use (British Standard 5724, Safety of Medical Equipment Part I; and specifically in relation to the Department of Health and Social Security Enuresis Alarm Performance specification, RE/1004/03). No child had 'buzzer ulcers'. Only one unit-an accessory unit, the Silent Wakener-was considered too poor in design to be recommended for purchase. This is an optional accessory provided with the Headingley alarm. It is a vibrator in a 'flying saucer' shaped container which is placed under the patient's pillow in the hope that fewer members of the household will be disturbed when the child wakes up. This hope was not fulfilled in our experience and although it was effective in waking patients, the internal battery was over worked and replacement was a 'fiddly' process. It is stressed, however, that the Headingley alarm itself is extremely well constructed; good clinical results were achieved, but as with the other alarms, the number of patients using the alarm were too few to allow any definite conclusion in relation to clinical performance. If parental attitudes are taken into account, however, the Eastleigh and Urilarm De-Luxe models had distinct advantages in respect of false alarms, breakdowns, and durability of mats. These are the factors most likely to maintain enthusiasm in the use of the conditioning apparatus. Confidence in the reliability of the apparatus was an important factor in retaining cooperation of the parents.

In our series an initial arrest of bed wetting in 45 children $(45 \%)$ was disappointingly low, as other trials have reported an initial success rate of approximately $70 \% .^{12}$ Nine of the 45 children, $(20 \%)$ subsequently relapsed within six months of stopping the conditioning treatment. Relapsers and non-responders were not offered a second course of conditioning treatment. It would be inappropriate to use the clinical success rate achieved by each type of alarm as the solitary criterion for a 'best buy' selection because only a small number of children were allocated to each alarm. Furthermore, certain factors such as social conditions and the psychological state of the child were not taken into consideration.

We thank the Scottish Home and Health Department for providing financial assistance for this project; the nursing staff of the Day Bed
Area at the Royal Hospital for Sick Children, Glasgow; and Mrs M McGibbon for secretarial help.

\section{References}

' Meadow SR. Help for bed-wetting. Edinburgh: Churchill Livingstone, 1980:24.

${ }^{2}$ Dische S. Management of enuresis. Br Med J 1971;ii:33-6.

${ }^{3}$ Forsythe WI, Redmond A. Enuresis and electric alarm: study of 200 cases. Br Med J 1970;i:211-3.

${ }^{4}$ Meadow SR. Practical aspects of the management of nocturnal enuresis. In: Kolvin I, MacKeith RC, Meadow SR, eds. Bladder control and enuresis. London: Heinemann, 1973:181-8. (Clinics in Developmental Medicine nos 48/49)

5 Lovibond SH. Conditioning and enuresis. Oxford: Pergamon Press, 1964.

Correspondence to Dr K M Goel, Royal Hospital for Sick Children, Yorkhill, Glasgow G3 8SJ.

Received 7 February 1984

\section{Commentary}

\section{ROY MEADOW}

Department of Paediatrics and Child Health, St James's University Hospital, Leeds

Those treating children with enuresis are likely to achieve the best results if they accustom themselves to one or two types of enuresis alarm only. In that way they become expert with the equipment and can arrange for satisfactory spares and servicing. Using nine different alarms during the same period must have been difficult for the Glasgow workers, which is perhaps why the overall success rate was lower than that reported for clinics using only one or two types of alarm.

The comparisons are limited to alarms which use a wet detector pad or mat on which the child sleeps, connected to an alarm near the bed. There are available now small wet detector strips which may be attached to the child's pants and connected to an alarm which is either pinned to the shoulder or worn on the wrist (like a watch). It is not known, however, whether this newer type of alarm is as effective as one which the child can only silence by getting out of bed to switch off.

Although the small numbers of children using each type of alarm prevent a strict comparison of efficiency in relation to treatment outcome, nevertheless, the Glasgow workers and the parents involved end up with clear preferences. Readers accustomed to using enuresis alarms will not be surprised to learn that sturdiness and reliability emerge as the paramount needs. Such reliability is even more imperative when alarms are owned by a 